Original Research Paper

\title{
Model Identification and Wall-Plug Efficiency Measurement of White LED Modules
}

\author{
Ahmed Zurfi and Jing Zhang \\ Department of Systems Engineering, University of Arkansas at Little Rock, Little Rock, AR, USA
}

Article history

Received: 24-03-2016

Revised: 30-04-2016

Accepted: 06-06-2016

Corresponding Author:

Ahmed Zurfi

Department of Systems

Engineering, University of

Arkansas at Little Rock, Little

Rock, AR, USA

Email: ajabbas@ualr.edu

\begin{abstract}
In this study, an experimental method is developed to measure the Wall-Plug efficiency of white LED modules without using any apparatus or sensors to measure the intensity of light. The tested LED module consists of a white LED chip-on-board affixed on a heatsink. The proposed method is mainly based on thermal and electrical models of the LED module. Measurements of thermal and electrical power are implemented instead of optical power. The presented method is not intended to replace the existing conventional techniques used to obtain optical and thermal characteristics of LEDs, but it provides a simplified way to evaluate the Wall-Plug efficiency of white LED modules under pragmatic operational conditions. In this method, the parameters of the wall-plug efficiency model of an LEDheatsink module are identified. Then, the model is applied to evaluate the efficiency at operating conditions of different heatsink temperature and input current. A $9 \mathrm{~W}$ Cree $\odot$ XLamp white LED was tested at an ambient temperature of $23^{\circ} \mathrm{C} \pm 1$. Experimental results revealed that the parameters of the efficiency model can be extracted using the proposed method without measurement of optical power.
\end{abstract}

Keywords: Light Emitting Diode, Wall Plug Efficiency, Solid State Lighting, Thermal Resistance

\section{Introduction}

Lighting loads consume about $20 \%$ of the total electric power generated in the U.S. (Azevedo et al., 2009) and 5\% of the average of households electric energy consumption comes from lighting ("Tips: Lighting," 2014). Therefore, the efficiency of electric light sources represents a crucial factor that significantly affects the efficiency of the power system and impacts the assessment of households' energy bills. Accordingly, careful consideration should be taken in choosing an energy efficient light bulb among the vast selections of the existing lighting technologies including incandescent bulbs, fluorescent lamps, High Intensity Discharge (HID) lamps, Compact Fluorescent Light (CFL) bulbs as well as Solid State Lighting (SSL) using Light Emitting Diodes (LEDs). In 2007, the U.S. Department of Energy (DoE) issued new energy conservation standards by the Energy Independence and Security Act (EISA-2017) that imposes on the incandescent bulbs to be more efficient and consume $30 \%$ less energy. According to the new requirements, (100, 75, 60 and 40) Watt incandescent bulbs have been gradually phased out between Jan 1st, 2012 and Jan 1st, 2014 (Lippert, 2009). Moreover, General Electric, one of the world's largest lighting manufacturers, has recently announced that it would discontinue manufacturing and marketing CFL bulbs by the end of 2016 (Cardwell, 2016). Therefore, more attention has been focused on LED lights as a competitive alternative technology owing to their attractive advantages. In particular, high power LEDs are supposed to dominate the lighting technologies by 2025 (Xiong et al., 2009; Azevedo et al., 2009). The recent two decades have witnessed vast improvements in LED manufacturing technology such as the development of new semiconductor materials and advanced fabrication techniques to produce high luminous efficacy devices for white illumination applications (Narendran et al., 2005). Since then, the LED efficiency has increased considerably. The U.S. DoE has reported an increase in the efficiency of commercial LED products to three times between 2005 and 2013 (USDEBTP, 2013). 
The LED's Wall-Plug (WP) efficiency or the power efficiency (these two terms will be used interchangeably in the sequel) represents a clear performance index that describes the energy conversion in the LED and it can be used as a selective parameter to compare LED devices. The WP efficiency provides a comprehensive definition of how much optical power the device can radiate when it is supplied with a certain electrical power (Heikkilä et al., 2010). However, it does not detect fluctuations in the light wavelengths due temperature shifts and aging that are only possible to measure with spectral measurements to check fluctuation in color coordinates according to CIE 1931 and chromaticity of white light. In fact, information about the WP efficiency is not very well stated in an LED datasheet. Manufacturers usually provide technical information about the LED luminous intensity, current and voltage ratings and thermal resistance at typical temperature conditions (ATAN, 1999). Therefore, to evaluate the power efficiency; the optical power (in Watt) of the LED needs to be measured using a special optical equipment (Park and Lee, 2005; Raypah et al., 2016). Besides, the power efficiency of an LED is significantly affected by the junction temperature (Poppe and Lasance, 2009). As a result, the measurement of the junction temperature is a major obstruction in modeling the power efficiency due to the device packaging (Qin and Hui, 2010). However, many indirect methods to measure junction temperature have been presented in the literature such as the calibration method using a temperature sensitive parameter (Roscam Abbing and Pertijs, 2011). Other indirect methods were also listed in (Chen et al., 2012). All of the introduced techniques necessitate sophisticated apparatuses to provide thermal and optical characterization of the LED. In (Chen et al., 2012), a serious effort has been made to come up with a simplified procedure to estimate a model of the WP efficiency in terms of the heatsink temperature and the electrical input power. However, it requires preliminary optical and electrical tests using a special measuring system.

In this study, we present a novel method to estimate the parameters of the LED WP efficiency model by measuring external electrical and thermal parameters. Without the need to measure optical output power, the model was practically verified to conveniently calculate the power efficiency at different points within the device operating range.

The rest of the paper is organized as follows. In section 2, the considered model for WP efficiency is discussed. Section 3 describes the tested module, the experimental testing setup and the applied procedures. Then, in section 4 the experimental results and the extracted model parameters are shown and finally, the main results and conclusion for this work are shown in section 5 .

\section{WP Efficiency Model}

The WP efficiency of an LED describes how much optical power can be obtained from the device when it is fed with a certain input electrical power. It is the ratio of the output optical $\left(P_{o p t}\right)$ and the input electrical $\left(P_{i n}\right)$ powers (Ching et al., 2012), as shown in (1):

$\eta_{W P}=\frac{P_{o p t}}{P_{i n}} \times 100 \%$

The input electrical power is simply the product of the diode voltage $\left(V_{d}\right)$ and the current crossing it $\left(I_{d}\right)$, so $P_{i n}=V_{d} I_{d}$. For white LEDs, electrical input power is mainly transformed into optical power and thermal dissipation $\left(P_{\text {diss }}\right)$ (Poppe et al., 2006; USDEBTP, 2007). Figure 1 shows the structure of a white LEDheatsink module and its power conversion process. Therefore, the WP efficiency can be expressed in terms of thermal power as:

$\eta_{W P}=\frac{V_{d} \cdot I_{d}-P_{d i s s}}{V_{d} I_{d}} \times 100 \%$

According to (2), the WP efficiency for a LEDheatsink module can be determined by measuring $V_{d}$, $I_{d}$ and $P_{\text {diss. }}$. In other words, it is possible to estimate the optical output power by indirect measurements; it is not mandatory to directly measure the optical power.

Basically, the WP efficiency depends on two parameters; the device heatsink temperature $T_{h s}$ and input power $P_{i n}$. The effect of each parameter on the WP efficiency can be investigated separately with the other parameter maintained constant. There are linear and quadratic decreasing relations between WP efficiency and heatsink temperature and input power, respectively. The WP efficiency model of an LEDheatsink module used in this study was proposed by (Chen et al., 2012) as:

$\eta_{W P}\left(T_{h s}, P_{i n}\right)=\frac{\left(a T_{h s}+b\right)\left(A P_{i n}^{2}+B P_{i n}+C\right)}{\mu} \%$

where, $T_{h s}$ is the heatsink temperature and $a, b, A, B, C$ and $\mu$ are parameters to be experimentally identified. Equation 3 shows that $\eta_{W P}$ depends on both the heatsink temperature and the LED input power. Fortunately, both magnitudes can be directly measured. 

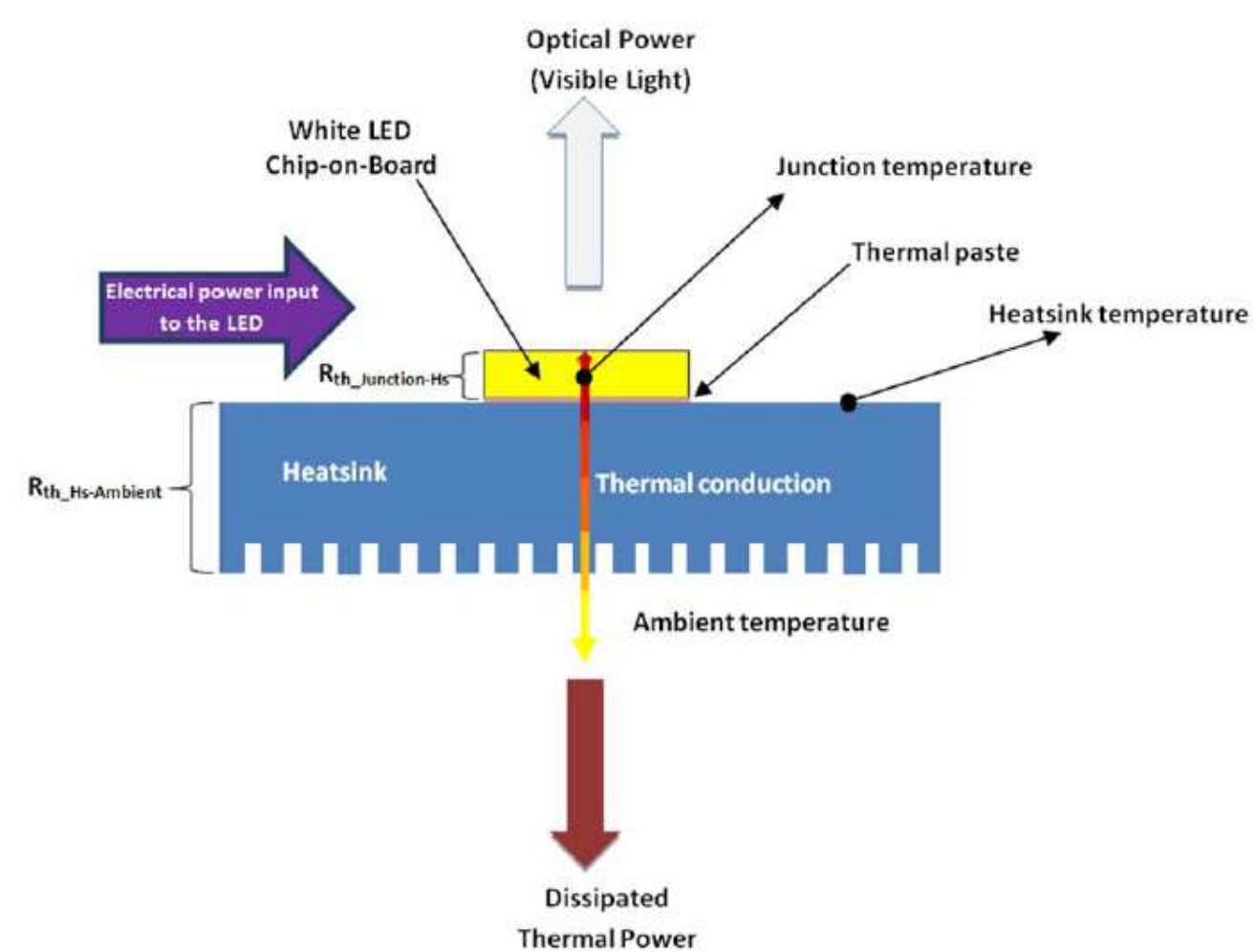

Fig. 1. The structure of the Module under Test and Energy Conversion Process in the White LED

\section{Experimental Method and System}

The proposed experimental method to identify the parameters in the adopted model takes two steps:

Step 1. By keeping the LED input power constant $P_{i n}=P_{i n, 0}$, we set different heatsink temperatures and measure $P_{\text {diss }}$ for each temperature setting. Next, Equation 2 is used to obtain $\eta_{W P}\left(T_{h s}, P_{i n, 0}\right)$. And finally, the parameters $\mathrm{a}$ and $\mathrm{b}$ are obtained through Equation 4:

$\eta_{W P}\left(T_{h s}, P_{i n, 0}\right)=a T_{h s}+b$

Step 2. By keeping the heatsink temperature constant $T_{h s}=T_{h s, 0}$ (that is, keeping constant $P_{\text {diss }}$ ), we set several input powers and by using Equation 2 we get $\eta_{W P}\left(T_{h s 0}, P_{i n}\right)$. And finally, through Equation 5 we obtain parameters $A, B$ and $C$ :

$\eta_{W P}\left(T_{h s 0}, P_{i n}\right)=A P_{i n}^{2}+B P_{i n}+C$

By combining Equation 4 and 5 together to form Equation 3 and calibrating at the test point. $\eta_{W P}\left(T_{h s 0}, P_{i n, 0}\right)$ to find $\mu$, the parameters of model Equation 3 can be identified.
The key factor in the experimental procedure is to be able to measure $P_{\text {diss }}$. It is done by using the differential method presented in our previous work (Zurfi et al., 2014), where two exactly equal heatsinks are used. The temperature of both heatsinks are controlled by an Automatic Temperature Controller (ATC) and the LED to be tested is installed on one of them. The LED is supplied with monitored input power and the ATC is used to set the temperature of both heatsinks to the same target value. Heating of standalone heatsink is caused only by ATC. However, LED power dissipation is added to the effect of ATC in the other heatsink. This way, the difference between powers applied by ATC to both heatsinks provides $P_{\text {diss }}$ of LED for that target temperature. The procedure of the measurement of $P_{\text {diss }}$ is shown in Fig. 2 and explained in the following paragraphs.

More than $90 \%$ of thermal power losses generated in a high power LED device are dissipated to ambient through heatsink where it is attached (Christensen and Graham, 2009). Therefore, in this study, the amount of heat generated in the device is estimated by measuring only on the heatsink. In steady state, thermal models of the two mentioned systems are described as follows (Poppe and Lasance, 2009).

System A: The temperature of heatsink A is: 


$$
T_{h s A}=T_{a m b}+R_{A}\left(P_{h A}+P_{d i s s}\right)
$$

where, $R_{A}$ is the thermal resistance of the heatsink A, $T_{a m b}$ is the ambient temperature and $P_{h A}$ is the conduction loss of the power MOSFET A

System B: The temperature of the heatsink B is:

$$
T_{h s B}=T_{a m b}+R_{B} P_{h B}
$$

where, $R_{B}$ is the thermal resistance of heatsink B and $P_{h B}$ is MOSFET B conduction loss. For the same heatsinks, $R_{A}=R_{B}$. When balance between the temperature of heatsink $\mathrm{A}$ and heatsink $\mathrm{B}, T_{A}=T_{B}$, is achieved by the ATC, it signifies that the heat dissipation in both systems is equal. Therefore, the thermal power dissipation of the LED can be calculated as:

$$
P_{\text {diss }}=P_{h B}-P_{h A}
$$

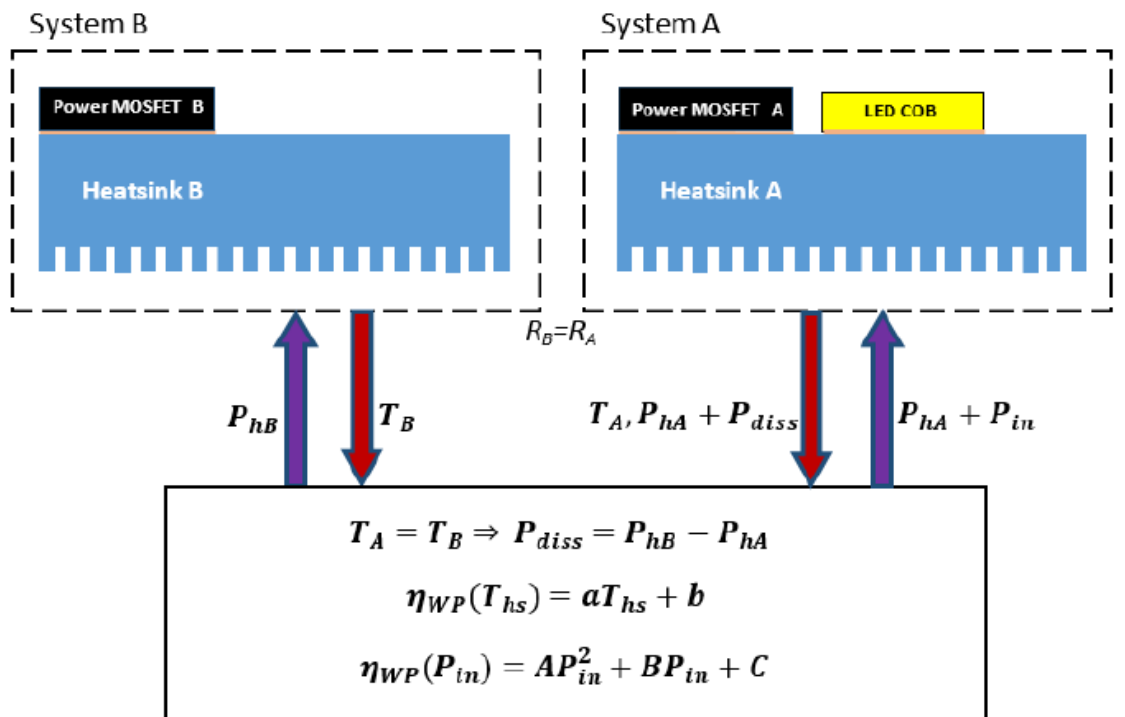

The Automatic Temperature Controller (ATC)

Fig. 2. Measurement of the thermal power dissipated in the LED using the differential method

ATC

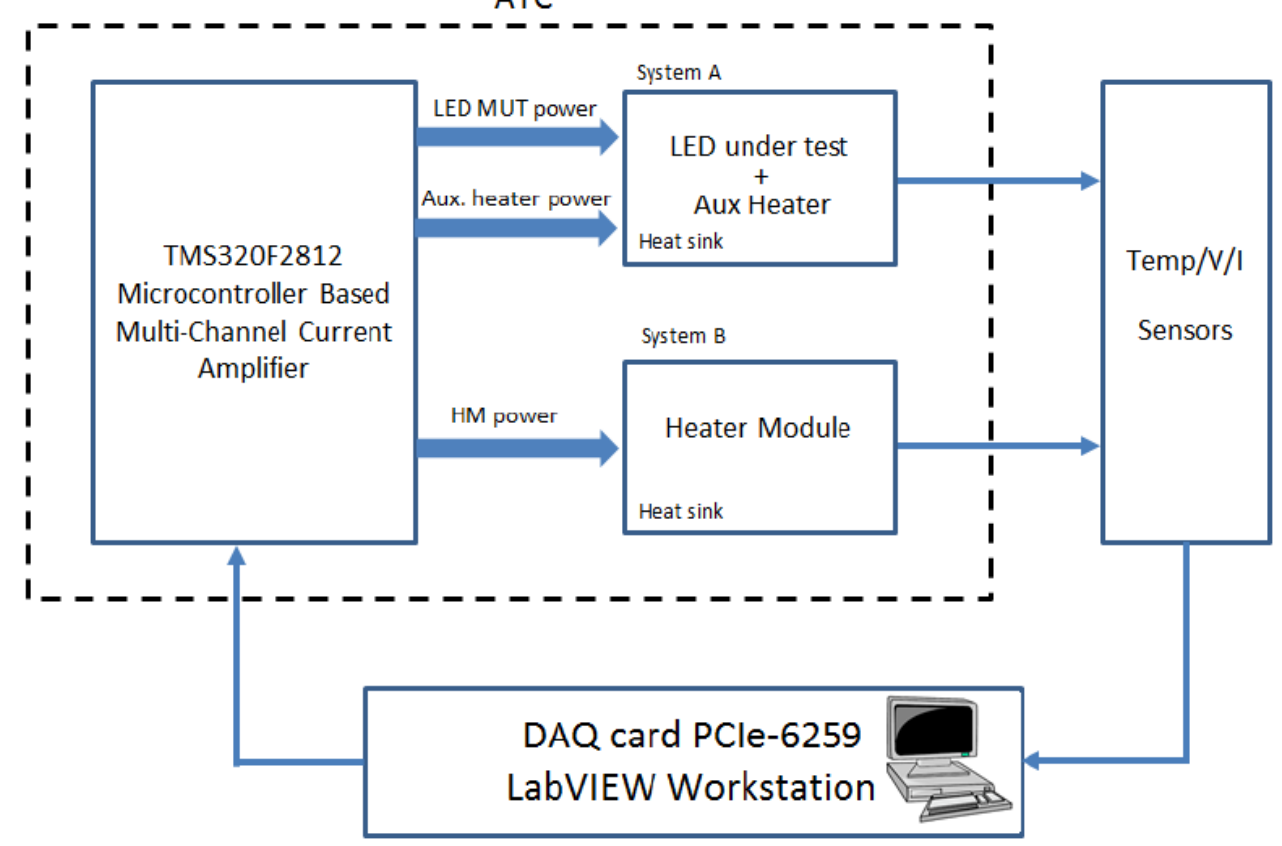

Fig. 3. Block diagram of the test system depicting the two 


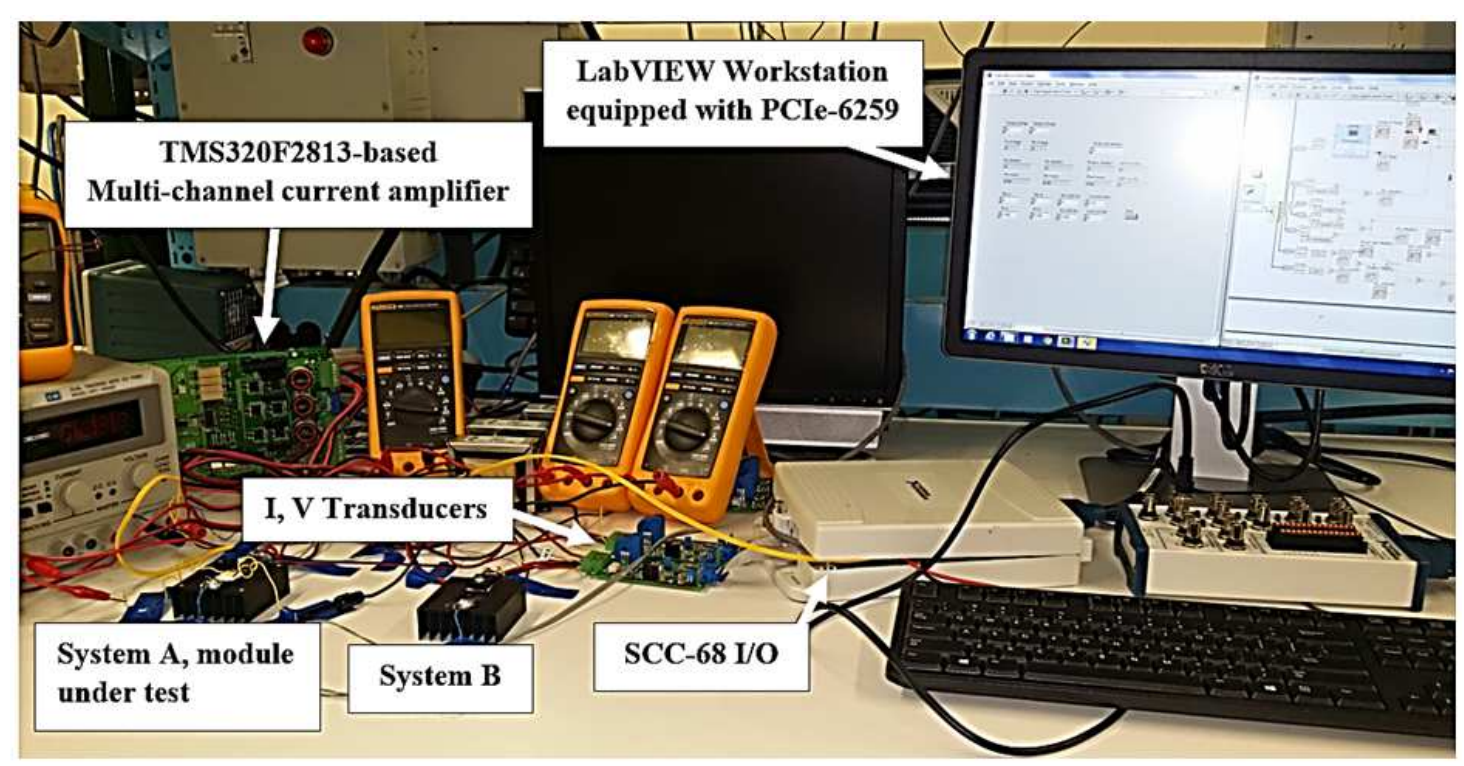

Fig. 4. Photograph of the test platform

An ATC with three power control channels was developed based on a TMS320F2813 microcontroller from Texas Instruments, Inc. The purpose of the ATC is to control the LED input power and the power injected into heaters installed on both heatsinks. Heaters are power MOSFETs (model IRFPF40, Vishay Siliconix) which work in turn-on state with a turn-on resistance of 2.5 ohms. Figure 3 shows the block diagram of the experimental setup. System A consists of the LED under test and the power MOSFET, both mounted on the heatsink. System B consists simply of MOSFET and the heatsink. Sensors to measure temperature on heatsinks and voltagecurrent on LED complete the setup. Also, a LabVIEW program for real-time data acquisition and humanmachine interface was developed in a workstation with a LabVIEW data acquisition board PCIe-6259. Figure 4 shows a photograph of the developed test platform.

\section{Experimental Results}

A 9 W Cree Xlamp white chip-on-board LED mounted on a heatsink was tested. Thermal paste was used to assure good thermal conductivity between the LED package and the heatsink. Tests were performed at uncontrolled ambient temperature of $23 \pm 1^{\circ} \mathrm{C}$. No means to control ambient temperature were applied to mimic the real operating conditions.

In order to extract the parameters of the WP efficiency defined in Equation 2, first the relation of the efficiency with heatsink temperature needs to be obtained. At constant LED power input of $P_{i n, 0}=6.3$ $\mathrm{W}$, the temperature of heatsink $\mathrm{A}$ is increased in different steps by changing the power supplied to heater A. At each temperature step; the efficiency is evaluated by Equation 2 in the proposed method. Then, the coefficients $a$ and $b$ are identified by using Matlab fitting function. Figure 5 shows the measured relation between WP efficiency and heatsink temperature. It can be observed that the WP efficiency decreases linearly with the heatsink temperature. Then, the relation between the WP efficiency and power input was obtained heatsink temperature of $T_{h s, 0}=58^{\circ} \mathrm{C}$ and the coefficients $A, B$ and $C$ were identified in the same procedure. Figure 6 shows the measured WP efficiency versus power input. It can also be noticed that the efficiency decreases in a quadratic fashion with power. To obtain the complete model, the parameter $\mu$ must be evaluated from the obtained results by matching the WP efficiency $\eta_{W P}\left(T_{h s, 0}, P_{i n, 0}\right)$ calculated in Equation 3 with the measured value. All the model coefficients of WP efficiency in Equation 3 were listed in Table 1.

Then, the extracted model has been validated under different conditions of power input and heatsink temperature. Figure 7 shows a 3-D graph of the calculated efficiency versus both temperature and power within the device operating range.

Table 1. WP Efficiency extracted coefficients

\begin{tabular}{llllll}
\hline$a$ & $b$ & $A$ & $B$ & $C$ & $\mu$ \\
\hline-0.1818 & 35.157 & -0.0564 & -1.3638 & 34.847 & 24.6 \\
\hline
\end{tabular}




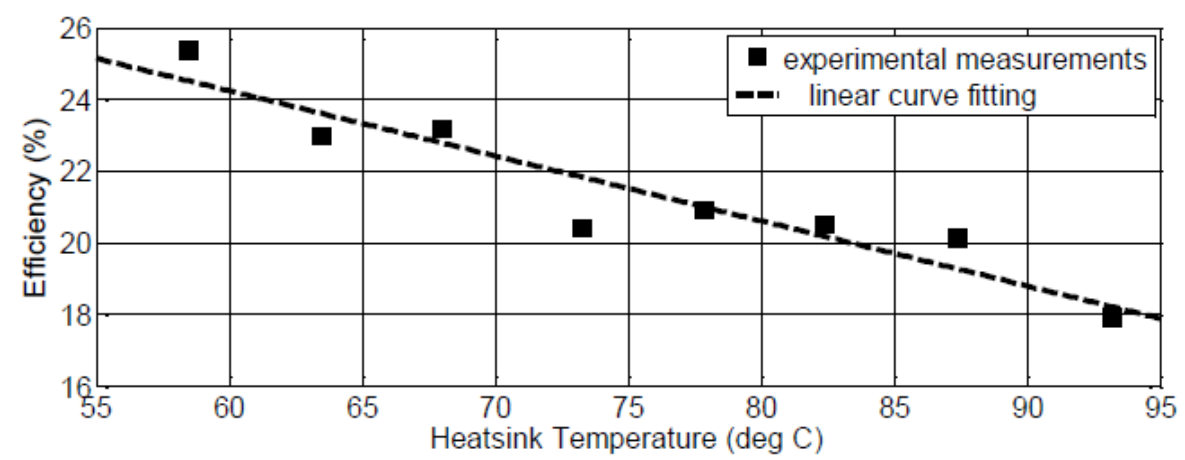

(a)

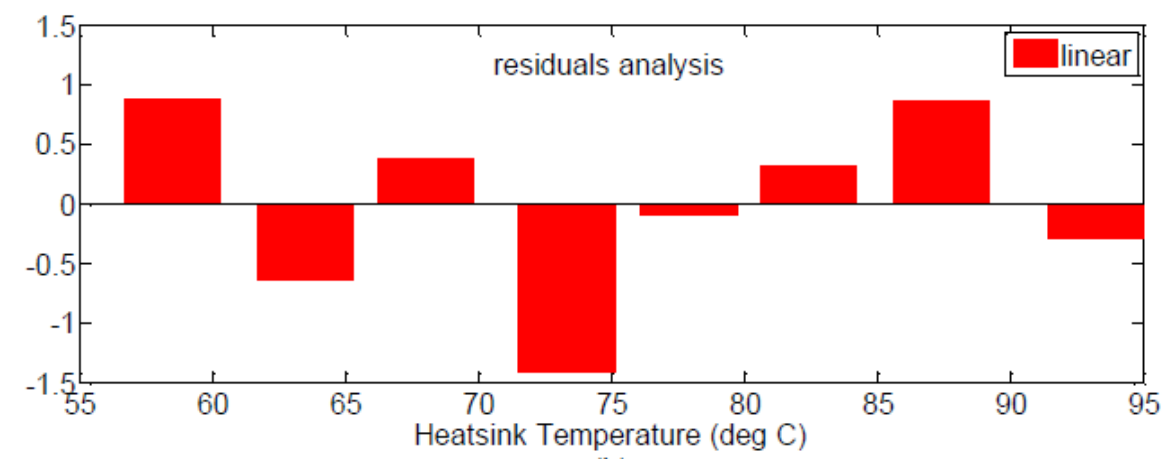

(b)

Fig. 5. Measured WP efficiency against heatsink temperature with constant power input. (a) Experimental results and the linear curve fitting. (b) residuals analysis of the curve fitting

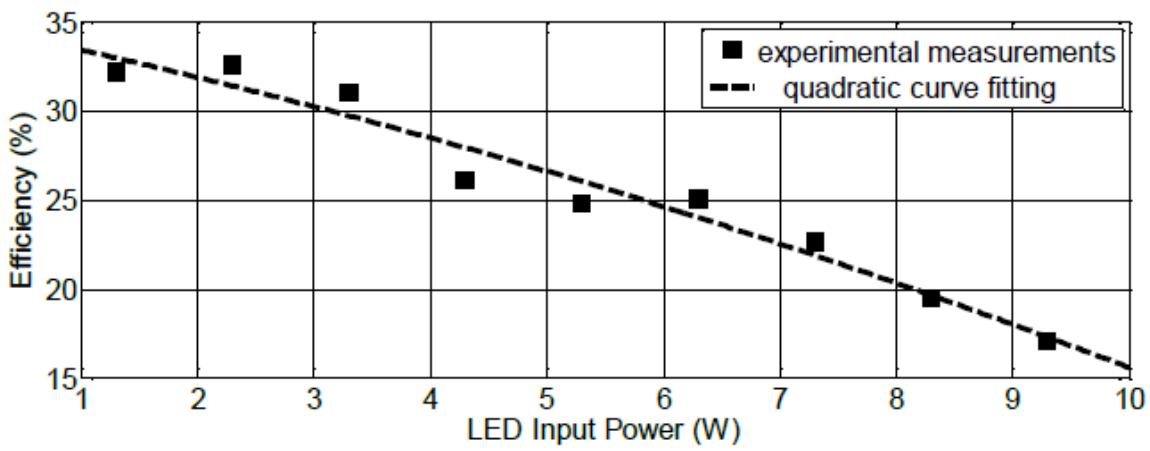

(a)

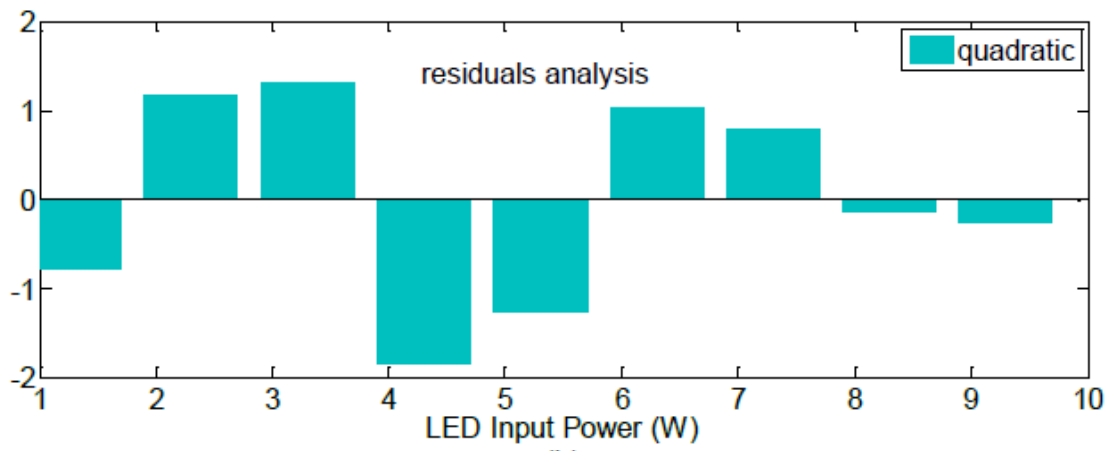

(b)

Fig. 6. Measured WP efficiency against the LED input power with constant heatsink temperature. (a) Experimental results and the quadratic curve fitting. (b) residuals analysis of the curve fitting 


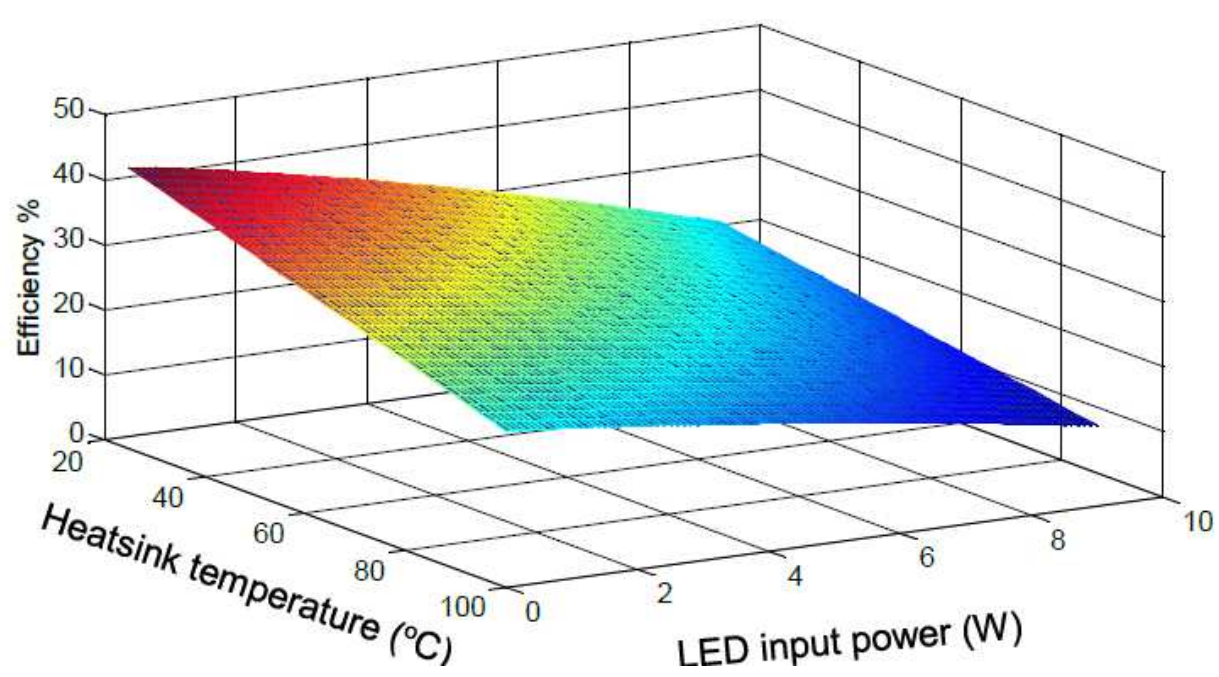

Fig. 7. WP efficiency at different conditions

\section{Conclusion}

This paper presents an experimental method to identify the parameters of the WP efficiency model of a white LED-heatsink module without measuring optical power output directly. With such a model, the WP efficiency of an LED-heatsink model can be evaluated under any operating conditions, which will be helpful for the design of an LED-heatsink module. In the presented method only heatsink temperature, LED voltage and current are measured and controlled during the experiments. Therefore, such an experimental method can be completed in any conventional laboratory for electrical engineering.

The key of the proposed method is to estimate the thermal power loss of an LED in the operation. A differential method was developed, in which two exact the same heatsinks with controlled heaters are used. By measuring the power required to keep the both heatsinks at the same temperature in steady state, the LED power loss can be estimated.

To confirm the effectiveness of the proposed method, a 9-Watt Cree Xlamp white LED mounted on a heatsink was used in the experiment. The experimental results are used to identify the parameters of WP efficiency of the LED-heatsink model.

It was obvious that the proposed method does not require optical measurements, but it has the disadvantage of requiring multiple voltage and current measurements at different temperatures making it less immediate than the optical measurements in an integrating sphere.

\section{Funding Information}

This work was supported, in part by, the Higher Committee for Education Development in Iraq (HCED).

\section{Authors' Contributions}

Both authors contributed to the preparation, development and publication of this work.

\section{Ethics}

The authors have no conflict of interest to reveal.

\section{References}

Azevedo, I.L., M.G. Morgan and F. Morgan, 2009. The Transition to Solid-State Lighting. Proc. IEEE, 97: 481-510. DOI: 10.1109/JPROC.2009.2013058

Cardwell, D., 2016. G.E. to phase out CFL bulbs. The New York Tmes. http://nyti.ms/23DMPpa

Chen, H.T., X.H. Tao and S.Y.R. Hui, 2012. Estimation of optical power and heat-dissipation coefficient for the photo-electro-thermal theory for LED systems. IEEE Trans. Power Electr., 27: 2176-83.

DOI: 10.1109/TPEL.2011.2165736

Ching, C.P., Z.Y. Lee, S.Y. Lee and M. Devarajan, 2012. Analysis on optical properties for various types of light emitting diode. Proceedings of the 10th IEEE International Conference on Semiconductor Electronics, Sept. 19-21, IEEE Xplore Press, Kuala Lumpur, pp: 388-91.

DOI: 10.1109/SMElec.2012.6417168

Christensen, A. and S. Graham, 2009. Thermal effects in packaging high power light emitting diode arrays. Applied Thermal Eng., 29: 364-71.

DOI: 10.1016/j.applthermaleng.2008.03.019

USDEBTP, 2013. Energy efficiency of LEDs. U.S. Department of Energy Building Technology Program. 
Heikkilä, O., J. Oksanen and J. Tulkki, 2010. The challenge of unity wall plug efficiency: The effects of internal heating on the efficiency of light emitting diodes. J. Applied Phys., 107: 1-6. DOI: $10.1063 / 1.3285431$

Lippert, J., 2009. A bright idea: New efficiency standards for incandescent and fluorescent lights. U.S. Department of Energy.

Narendran, N., Y. Gu, J.P. Freyssinier-Nova and Y. Zhu, 2005. Extracting phosphor-scattered photons to improve white LED efficiency. Phys. Status Solidi, 202: R60-62. DOI: 10.1002/pssa.200510015

ATAN, 1999. Operational considerations for LED lamps and display devices. Agilent Technologies Application Note 1005.

Park, J. and C.C. Lee, 2005. An electrical model with junction temperature for light-emitting diodes and the impact on conversion efficiency. IEEE Electron Dev. Lett., 26: 308-10. DOI: 10.1109/LED.2005.847407

Poppe, A., G. Farkas, V. Székely, G. Horváth and M. Rencz, 2006. Multi-domain simulation and measurement of power LED-S and power LED assemblies. Proceedings of the 22th Annual IEEE Semiconductor Thermal Measurement and Management Symposium, Mar. 14-16, IEEE Xplore Press, Dallas, TX., pp: 191-198. DOI: 10.1109/STHERM.2006.1625227

Poppe, A. and C.J.M. Lasance, 2009. On the standardization of thermal characterization of LEDs. Proceedings of the 25th Annual IEEE Semiconductor Thermal Measurement and Management Symposium, Mar. 15-19, IEEE Xplore Press, San Jose, CA., pp: 151-58.

DOI: 10.1109/STHERM.2009.4810757
Qin, Y.X. and S.Y.R. Hui, 2010. Comparative study on the structural designs of LED devices and systems based on the general photo-electro-thermal theory. IEEE Trans. Power Electr., 25: 507-13. DOI: 10.1109/TPEL.2009.2026752

Raypah, M.E, B.K. Sodipo, M. Devarajan and F. Sulaiman, 2016. Estimation of optical power and heat-dissipation factor of low-power SMD LED as a function of injection current and ambient temperature. IEEE Trans. Electr. Devices, 63: 408-13. DOI: 10.1109/TED.2015.2501840

Roscam Abbing, F.D. and M.A.P. Pertijs, 2011. Lightemitting diode junction-temperature sensing using differential voltage/current measurements. Proceedings of the IEEE Sensors, Oct. 28-31, IEEE Xplore Press, Limerick, pp: 861-64. DOI: 10.1109/ICSENS.2011.6127191

USDEBTP, 2007. Thermal management of white LEDs. U.S. Department of Energy Building Technology Program.

Tips: Lighting, 2014. U.S. Department of Energy. http://energy.gov/energysaver/tips-lighting

Xiong, W., X. Luo, S. Liu and T. Cheng, 2009. Temperature estimation of high-power light emitting diode street lamp by a multi-chip analytical solution. IET Optoelectr., 3: 225-32. DOI: 10.1049 /iet-opt.2008.0068

Zurfi, A., D. Tompkins and J. Zhang, 2014. Efficiency measurement of white LED devices. Proceedings of the 40th Annual Conference of the IEEE Industrial Electronics Society, Oct. 29-Nov. 1, IEEE Xplore Press, Dallas, TX., pp: 1434-1439. DOI: 10.1109/IECON.2014.7048690 